\title{
The Use of the Total Electron Content Measured by Navigation Satellites to Estimate Ionospheric Conditions
}

\author{
Olga Maltseva and Natalia Mozhaeva \\ Institute for Physics, Southern Federal University, St. Stachki 194, Rostov-on-Don 344090, Russia \\ Correspondence should be addressed to Olga Maltseva; mal@ip.rsu.ru
}

Received 20 July 2016; Accepted 6 September 2016

Academic Editor: Sandro M. Radicella

Copyright (C) 2016 O. Maltseva and N. Mozhaeva. This is an open access article distributed under the Creative Commons Attribution License, which permits unrestricted use, distribution, and reproduction in any medium, provided the original work is properly cited.

\begin{abstract}
Measurements of delays of the signals radiated by transmitters of navigational satellites allow us to obtain the total electron content (TEC). In addition, measurements of TEC allow solving problems such as development of local, regional, and global models of TEC and correction of ionospheric delay for increasing accuracy of positioning. Now, it is possible to set the task of calculation of critical frequency foF2 with the use of experimental values of TEC in a global scale. For this purpose it is necessary to know an equivalent slab thickness of the ionosphere $\tau$ which is a coefficient of proportionality between TEC and a maximum density of the ionosphere. The present paper is devoted to the analysis of investigation and utilization of this parameter. It is shown that (1) existing models of $\tau$ are not empirical and not always can provide an adequate accuracy of foF2 calculation, (2) experimental median $\tau$ (med) provides much larger accuracy of foF2 calculation than the empirical model and variations from day to day and allows filling gaps in the ionosonde data, and (3) it is possible to use a hyperbolic approximation and coefficient $K(\tau)$ for development of a global model of $\tau$.
\end{abstract}

\section{Introduction}

With the advent of navigation satellites, it became possible to measure the total electron content TEC of the ionosphere, which in turn is essential for the functioning of navigation, telecommunications, and other systems. For example, in paper [1], two categories of radio systems were described in terms of ionospheric dependence. The first category includes systems that rely on the critical frequency of the ionosphere foF2: MF and HF communication, HF broadcasting ("shortwave" listening), OTH radar surveillance, HFDF, and HF SIGINT. The operation of these systems requires knowing the behavior of this frequency. Systems of the second category, namely, satellite and navigation (e.g., GPS and GLONASS) communication, space-based radar and imaging, terrestrial radar surveillance, and tracking and others, are influenced by the ionosphere. If in the first case it is necessary to know the state of the ionosphere at the bottom side, namely, up to the maximum height of the layer $\mathrm{F} 2, \mathrm{hmF} 2$, in the second case it is necessary to know the density of electrons in the topside ionosphere (above hmF2) and higher up to the height of high-altitude satellites. A model profile of this part may be corrected by TEC. To solve this problem it is also necessary to know foF2; therefore, one of the most important applications of TEC measurements using navigation satellites is to estimate foF2. Traditionally, values of foF 2 are measured by ground-based ionosondes, but their network is sparse. Measurement of TEC has several advantages: a large number of signal receivers, the possibility of continuous, global monitoring, and availability of initial data using network. These advantages allow scientists to study local, regional, and global features of ionospheric behavior independently, quickly, and simultaneously. Definition of morphological and perturbed features has allowed promoting essentially in understanding of spatial and temporary variations of the ionosphere. TEC is widely used for development of local, regional, and global models of TEC, for example, [2-4], which are necessary for correction of ionospheric delays to increase accuracy of 
positioning $[5,6]$. With use of TEC ionospheric disturbance indexes were developed $[7,8]$. In the present paper the basic attention is given to problem of estimation of foF 2 using TEC measurements. To calculate foF2 using TEC it is necessary to know a proportionality coefficient between TEC and NmF2. This coefficient is an equivalent slab thickness $\tau$ of the ionosphere. This paper is devoted to joint use of the observational values of TEC(obs) and the equivalent slab thickness $\tau$ to estimate foF2. The opportunity of development of a global $\tau$ model is investigated.

\section{Methodology and Used Data}

To obtain ionospheric conditions, in particular, values of foF2, empirical models are widely used, for example, IRI and NeQuick. These models define an average condition of the ionosphere; however for functioning of modern systems it is necessary to know instantaneous values and variations of foF2 from day to day. In the present paper, the instantaneous values of TEC measured by means of navigating satellites are used to estimate these values and variations. The methodology of foF 2 estimation, used in this paper, consists of joint use of observational values TEC(obs) and an equivalent slab thickness $\tau$ of the ionosphere. The following options are considered: (1) $\tau$ (IRI) of the IRI model [9], (2) $\tau$ (NGM) of the Neustrelitz models, (3) the model of Muslim and coauthors [10], and (4) median $\tau$ (med) of observational values $\tau$ (obs). $\tau$ (IRI) is traditionally used [1113]. Besides, the IRI model is the international standard to which results of other models are usually compared. The model $\tau(\mathrm{NGM})=\mathrm{TEC}(\mathrm{NGM}) / \mathrm{NmF} 2(\mathrm{NGM})$ is actually used in [14] on the basis of Neustrelitz models for TEC and NmF2 $[15,16]$, but without sufficient validation. This model has been tested in [17]. It was obtained that use of $\tau(\mathrm{NGM})$ did not improve results of use of $\tau$ (IRI) in most cases. Authors of [18] complained that researchers develop ionospheric models but not a model of $\tau$. Meanwhile, authors of [17] only have shown the values for the 6 stations in different regions of the globe. Moreover, values of $\tau$ (obs) were calculated from ionospheric electron content IEC values, that is, in the range of heights from the bottom of the ionosphere to the height of $500 \mathrm{~km}$ while TEC is measured for the satellite altitude (about 20,000 km). The latest step has been done in [10], where a model of average values of $\tau$ was developed by expansion in Fourier series according to the TEC of 21 stations. For TEC, monthly averages of the global CODE map were taken, and for foF2, the monthly medians. To test the model, data of 13 stations were used in such a way as to get results for various latitude zones (low, mid, and equatorial). The results were obtained for quiet and disturbed conditions by comparison with the results of the IRI model that takes into account STORM factor. The assumptions made in developing the model are as follows: (1) a linear dependence of all parameters (TEC, foF2, $\tau$ ) on solar activity, (2) absence of longitudinal dependence of these parameters at the same local time LT, (3) transition from a geographic to a geomagnetic coordinates does not affect the dependence of parameter variations on LT, and (4) invariance of $\tau$ in quiet and disturbed conditions. Results were obtained for 5 magnetic storms of varying intensity in the period 2000-2014. They are described in detail for several stations and individual disturbances. The general conclusions are as follows: (1) the new model enables improved compliance with measurements compared with the model IRI-STORM in the mid- and low latitudes and (2) the model gives the deterioration in equatorial latitudes in quiet and disturbed conditions. However, as could be seen from Table 4 of paper [10], deterioration takes place in quiet conditions even for the midlatitude Chilton station and for the low-latitude Del'Ebre station. Probably, it is connected with that the assumptions, taken as a principle of model, are not absolutely strict. In particular, it is possible to show that $\tau$ (med) depends on solar activity in the nonlinear way. The authors themselves point out that the presence of longitudinal dependence can be the cause of the deterioration. Illustration of violation of the assumption (2) is given in Figure 1 for stations in different zones for March 2015. Figures are given for $\tau$ (med) and $\tau$ (IRI) in (a) midlatitude zone, (b) low latitudes, and (c) an equatorial region. Latitudes of couples of stations are very close. Couple Juliusruh-Novosibirsk belongs to midlatitudes and couple Nicosia-Kokubunji is located in low latitudes. Couple Sao Luis-Fortaleza is in the equatorial zone. Authors of [10] do not apply their model to high latitudes and auroral zones; however, as in the papers $[19,20]$ the possibility of using the IRI model in these areas was shown; results are given also for couple Tromsö-Amderma. The parameter, for which the plot is under construction, is moved in heading together with units of measurements. On an axis $x$, local time LT is postponed.

It is seen as a good agreement between the values of $\tau($ IRI) of two stations; however, large differences are between $\tau$ (med). Violation of condition (4) is illustrated in Figure 2 where values of $\tau$ (med) and $\tau$ (IRI), close to values in quiet conditions, and values $\tau$ (obs) in disturbed days are compared. Results are given for the etalon Juliusruh station and two moderate disturbances in July 2004 with a minimum of Dst $=-197 \mathrm{nT}$ and in December 2006 with a minimum of Dst $=$ $-147 \mathrm{nT}$.

Unlike the model [10] it is offered to investigate two possibilities: (1) hyperbolic approximation of $\tau$ (obs) and (2) use of a median $\tau$ (med) in comparison with $\tau($ IRI). Hyperbolic approximation $\tau$ (hyp) $=b 0+b 1 / \mathrm{NmF} 2$ [21] was chosen on the basis of visual similarity and simplicity of analytical representation. The illustration is given in Figure 3. In case of the ESA map dispersion is stronger.

Comparison is carried out by means of several types of deviations of the calculated values of foF 2 from observational foF2(obs). The first deviation concerns values of foF2(IRI) for the initial IRI model IRI. The second deviation concerns value of the critical frequency calculated with use of TEC(obs) and $\tau($ IRI). Values of $\tau($ IRI $)$ are obtained from a relation $\tau($ IRI $)=$ TEC(IRI)/NmF2(IRI). The use of experimental values $\mathrm{TEC}(\mathrm{obs})$ provides calculated values $\mathrm{NmF} 2($ calc $)=$ $\mathrm{TEC}($ obs $) / \tau(\mathrm{IRI})$ and foF $2(\tau \mathrm{IRI})=897 * \mathrm{SQRT}(\mathrm{NmF} 2($ calc $))$. The third deviation concerns value of the critical frequency calculated with use of TEC(obs) and $\tau$ (med). The following expressions are used: $\tau($ med $)=\operatorname{med}(\mathrm{TEC}(\mathrm{obs}) / \mathrm{NmF} 2(\mathrm{obs}))$, 

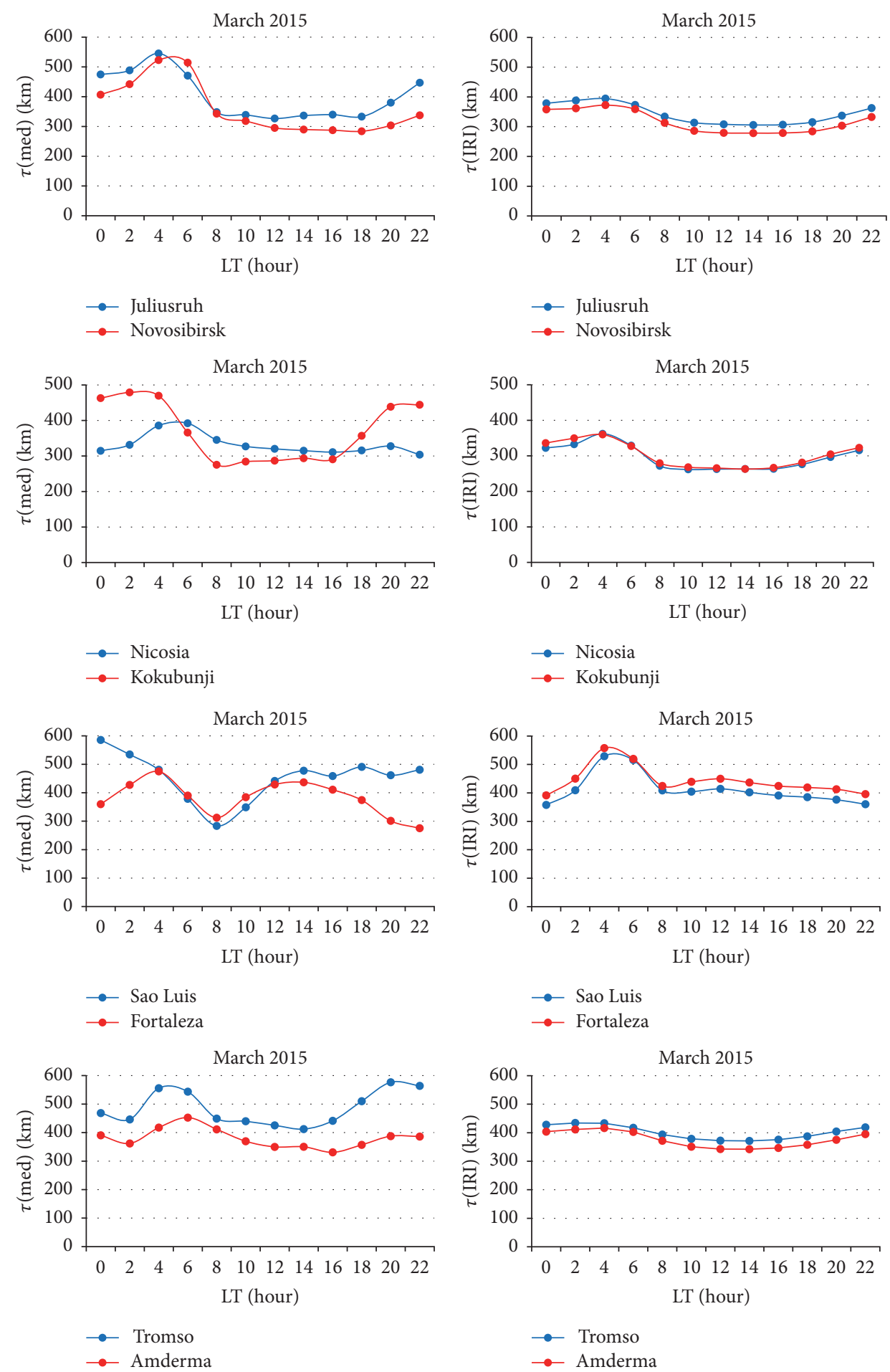

(a)

(b)

FIGURE 1: Longitude dependence of the behavior of $\tau$ at the same LT: curves show values of observational (a) and model (b) equivalent slab thicknesses for stations with close latitudes.

$\mathrm{NmF} 2($ calc $)=\mathrm{TEC}(\mathrm{obs}) / \tau(\mathrm{med})$, and foF $2(\tau \mathrm{med})=897 *$ $\mathrm{SQRT}(\mathrm{NmF} 2(\mathrm{calc}))$. Corresponding deviations are calculated as follows. The magnitude $|\Delta \mathrm{foF} 2(\mathrm{IRI})|=\mid$ foF2(obs) foF2(IRI)| represents the first deviation. The deviation $\mid \Delta$ foF $2(\tau($ IRI $))|=|$ foF $2(o b s)-$ foF $2(\tau$ IRI $) \mid$ is the second deviation, that is, a difference between foF2(obs) and values calculated with use of $\tau$ (IRI) and TEC(obs). The third deviation is written as $\mid \Delta$ foF $2(\tau$ (med) $)|=|$ foF2(obs) - foF2( $\tau$ med $) \mid$ 

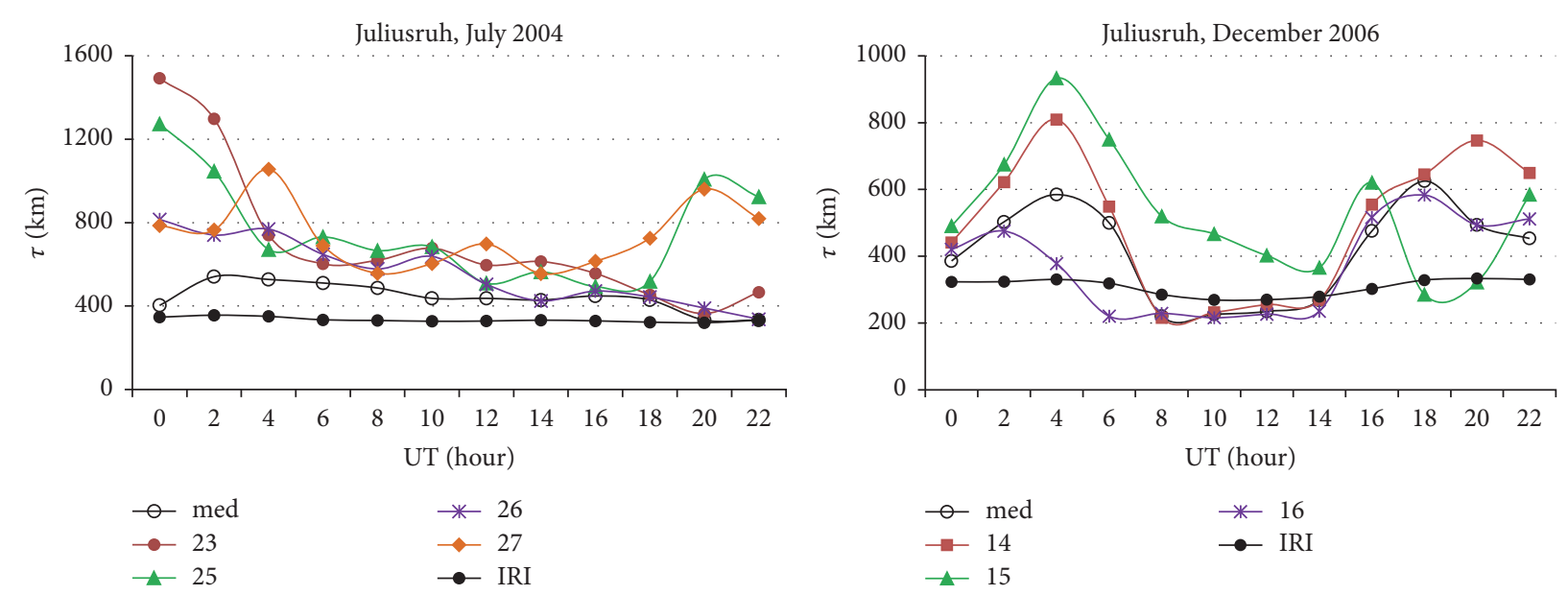

FIGURE 2: Illustration of differences of $\tau$ (obs) from $\tau$ (med) and $\tau$ (IRI) in disturbed days. Corresponding specified days are indicated by different colour in title of figures. Curves for $\tau$ (IRI) are shown by black dots. Curves for $\tau$ (med) are shown by hollow circles. Values of $\tau$ (obs) in specific disturbed days are given by curves of various colours, corresponding days are specified beside designations.

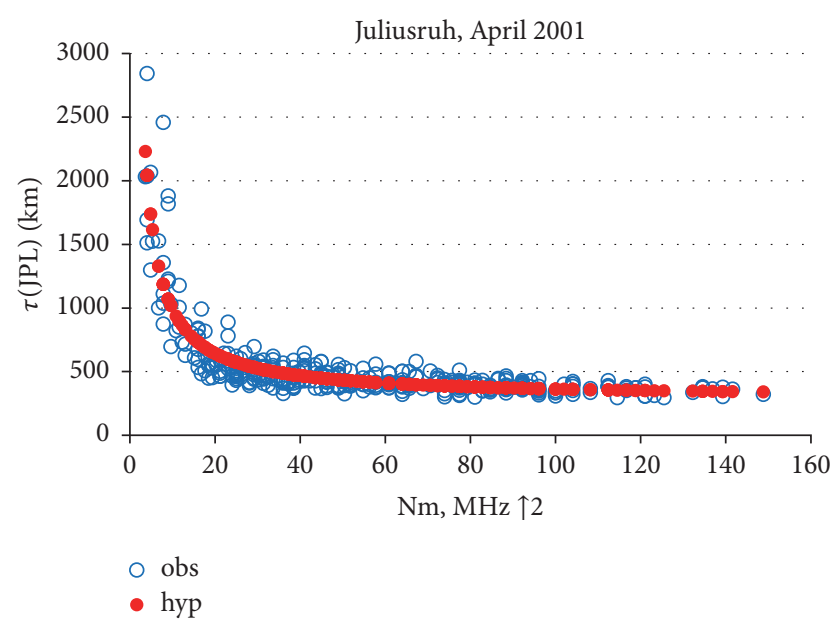

(a)

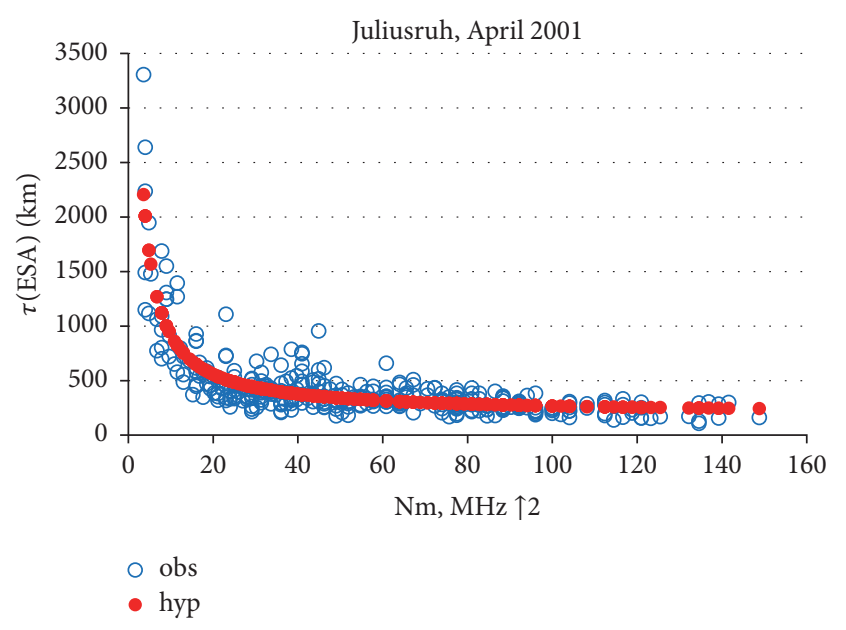

(b)

FIGURE 3: Dispersion of the equivalent slab thickness $\tau$ (obs) from regressive curve for various maps. Curves for various global maps JPL (a) and ESA (b) are presented for comparison. Magnitude Nm means foF2 ${ }^{2}$.

and is defined as a difference between foF2(obs) and values calculated with joint use of TEC(obs) and $\tau($ med). Monthly averages were calculated. To compare these deviations an efficiency coefficients of use of instantaneous TEC(obs) for calculation of instantaneous values of foF 2 are introduced. Coefficient $K \tau$ IRI $=\mid \Delta$ foF2(IRI) $|/| \Delta$ foF $2(\tau($ IRI $)) \mid$ is an efficiency coefficient of joint use of TEC(obs) and $\tau$ (IRI). Coefficient $K$ eff $=\mid \Delta$ foF2(IRI) $|/| \Delta$ foF2 $(\tau($ med $)) \mid$ is an efficiency coefficient of joint use of TEC(obs) and $\tau$ (med). Thus, coefficients $K \tau$ IRI and $K$ eff characterize how many times the compliance between the calculated and experimental values of foF2 using $\tau$ (IRI) and $\tau$ (med) as compared to the initial model is increased.

In this paper sources of observational data are IONEX files from ftp://cddis.gsfc.nasa.gov/pub/gps/products/ionex/ for TEC available with step 2 hour and SPIDR database http://spidr.ngdc.noaa.gov/spidr/index.jsp for foF2. The JPL map is used in most cases.

\section{Distinctions between Critical Frequencies foF2 Estimated with Use of TEC(obs) and Various Options of $\tau$}

It is obvious that differences of critical frequencies foF 2 , estimated with use of TEC(obs), are defined by distinction of values $\tau$. Values of $\tau$ (med) for the JPL map and $\tau$ (IRI) are presented in Figure 4 for several stations with long arrays of observations in various regions of the globe: Juliusruh (mid latitudes), Thule (a polar zone), and Ascension Island (an equatorial region) as the monthly averages for December and July of the corresponding year. Dots of various colours specify years. On an axis $x$, time UT is postponed. 

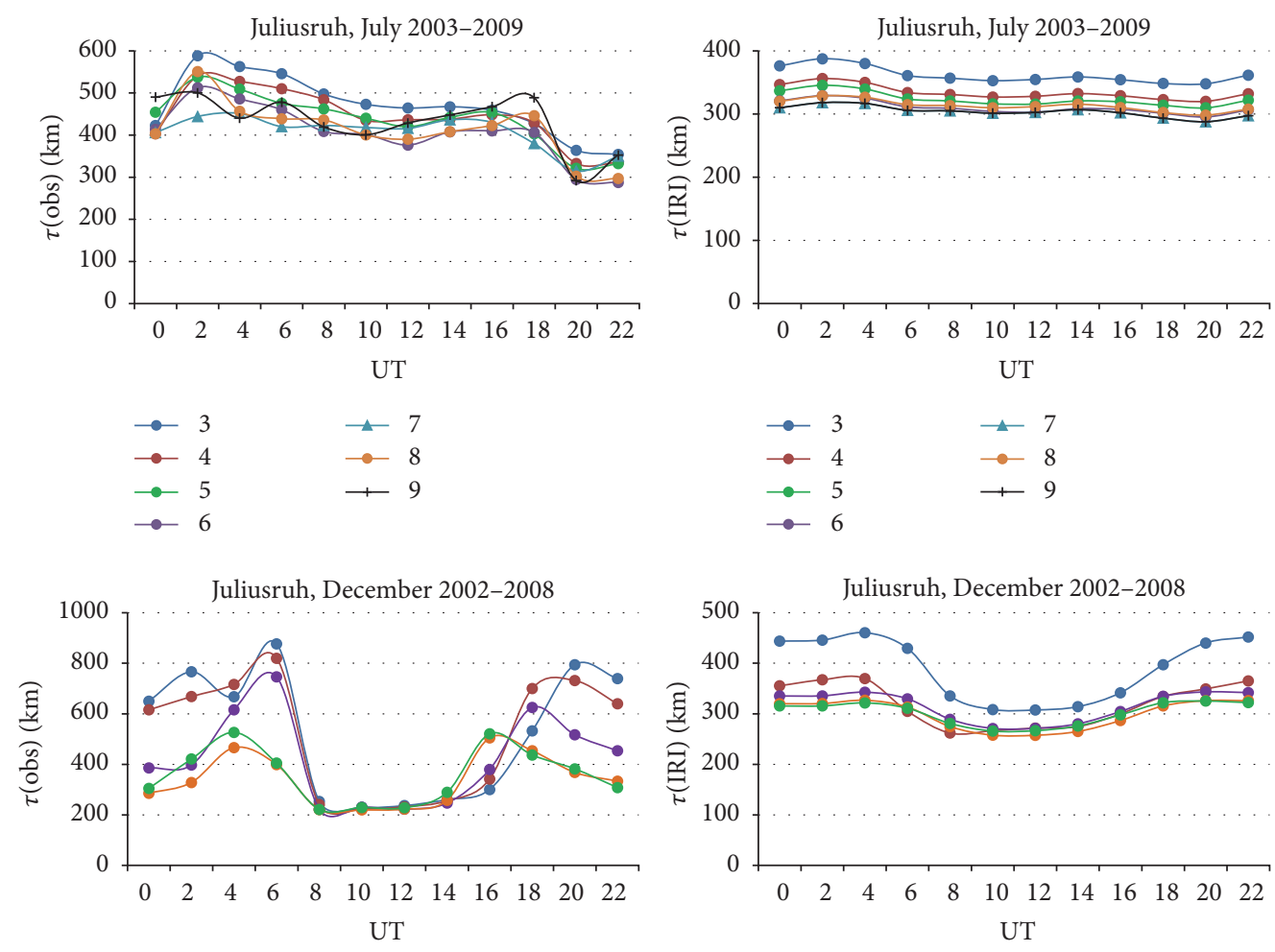
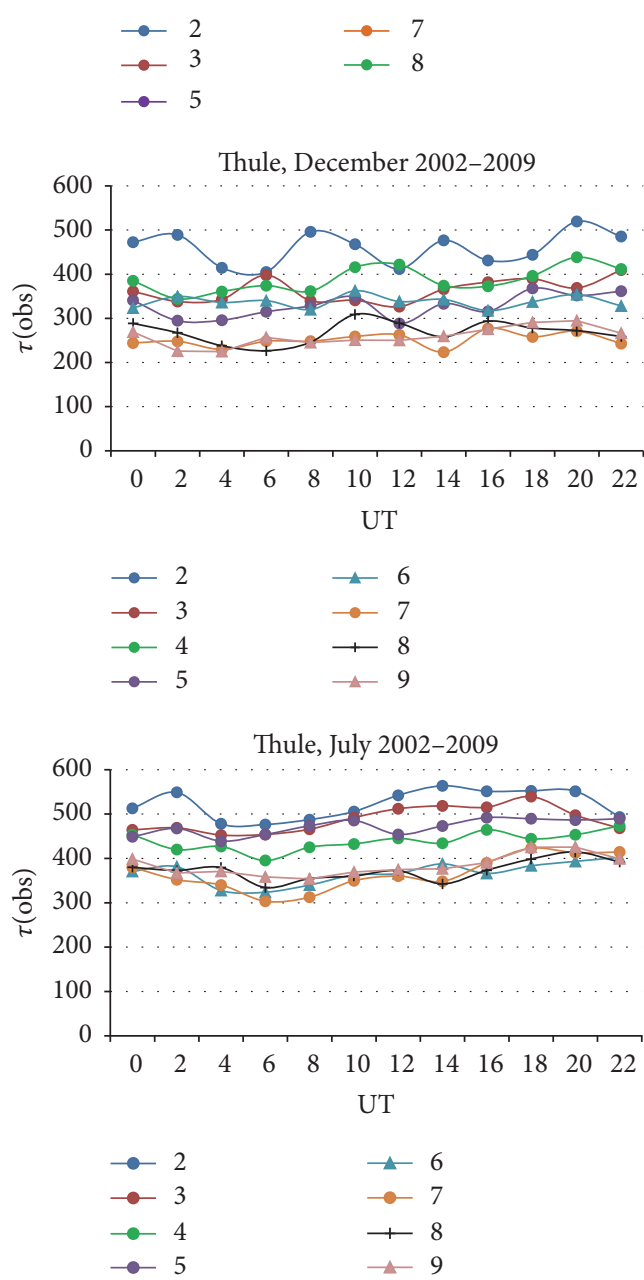
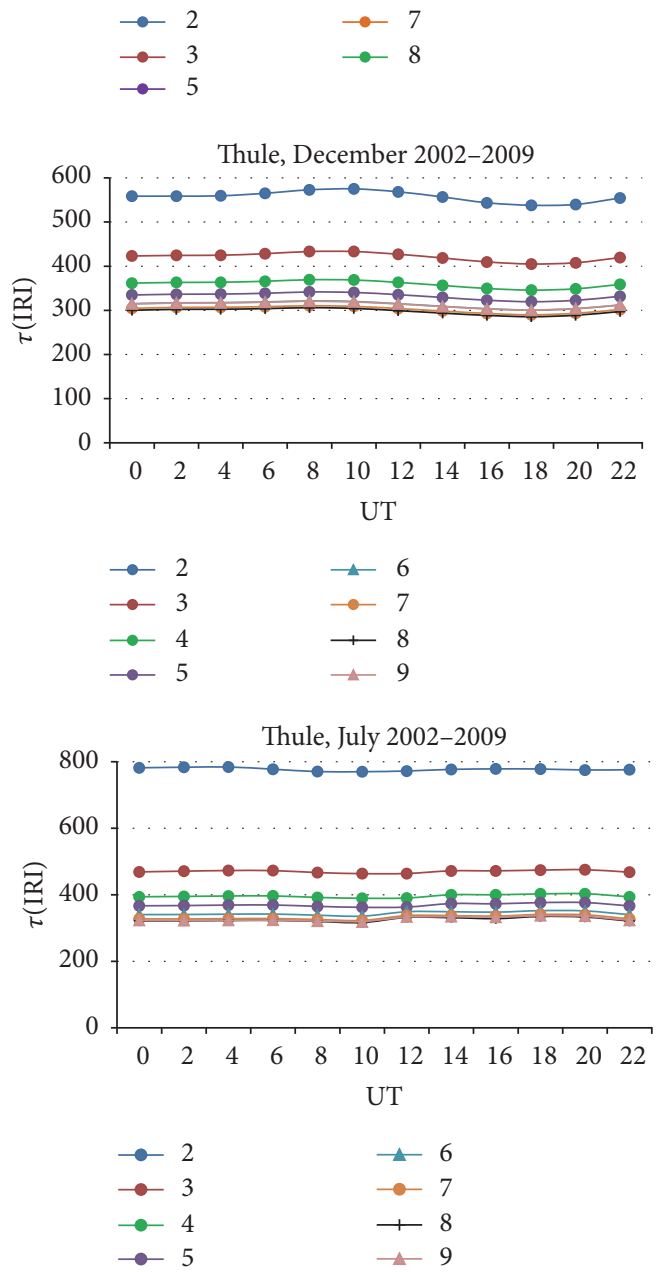

Figure 4: Continued. 

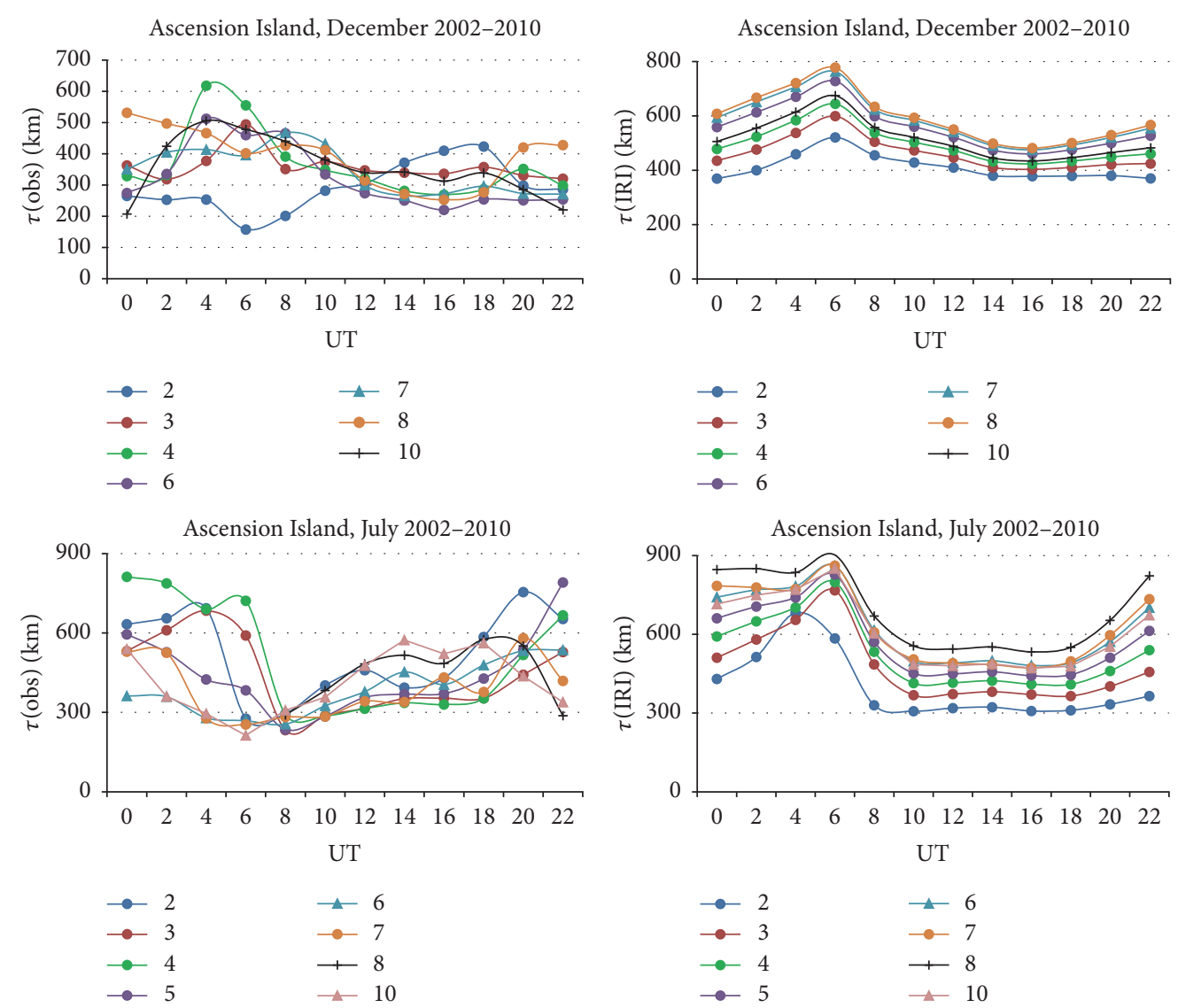

Figure 4: Comparison of equivalent slab thicknesses of the ionosphere for stations Juliusruh, Thule, and Ascension Island for several years. Curves are shown by dots of various colour.

The essential difference between $\tau$ (IRI) and $\tau$ (med) is obvious in some cases. This essential difference leads to corresponding difference between derived values of foF2. If values of $\tau$ (IRI) and $\tau$ (med) are close, deviations of foF2 will be small. Such cases are characteristic for the Thule station. Deviations of calculated foF2 from experimental values (Figure 5(a)) and efficiency coefficients Keff (Figure 5(b)) are shown in Figure 5 for stations Juliusruh, Thule, and Ascension Island. On left graphs black dots concern values of the initial IRI model (option of IRI2001 to distinguish from other options corr and NeQuick of the IRI2012 model). On Figure 5(b) this case corresponds to the curve $K=1$. Dark blue circles represent results for a case of use TEC(obs) and $\tau$ (IRI). Red dots correspond to a case of use of TEC(obs) and $\tau$ (med). If the ratio is equal to 1 , the use of the experimental value of TEC and the equivalent slab thickness provides the same results as the model itself without using TEC(obs). If the ratio is higher than 1 then the use of TEC gives better results than the model. If the ratio is less than 1 the use of TEC deteriorates results compared with the model. Coefficients Keff concern with a case of use of TEC(obs) and $\tau$ (med). Coefficients $K \tau$ IRI describe results for a case of use of TEC(obs) and $\tau$ (IRI).

In all cases the least deviations are provided at the use of TEC(obs) and $\tau$ (med), and coefficients Keff always are higher than 1. It testifies that the use of TEC(obs) provides better results than the initial model. Situation with use of TEC(obs) together with $\tau$ (IRI) is ambiguous. In most cases use of TEC(obs) and $\tau$ (IRI) improves results of the initial model (curves shown by dark blue circles in comparison with black curves) but at every station there are periods when the coefficients $K \tau$ IRI are less than 1 and the use of TEC(obs) deteriorates results of the initial model. These results lead to the following conclusions: (1) in the equatorial zone deviations are larger than in the mid- and high-latitude regions, (2) use of TEC(obs) together with $\tau$ (IRI) does not always improve correspondence between the calculated and experimental values of foF 2 in comparison with the initial IRI model, (3) use of $\tau$ (med) leads to more accurate values of foF2, and (4) the coefficient Keff is higher than 1.

\section{About the Possibility of Developing a Global Model of $\tau$ (med)}

To develop a model of $\tau$ (med) on a global scale there are possible several approaches: (1) the construction of surface function such as kriging from values of $\tau$ (med) at several points, (2) two-parameter model based on hyperbolic approximation $\tau$ (hyp) $=b 0+b 1 / \mathrm{NmF} 2[21]$ and the use of the 

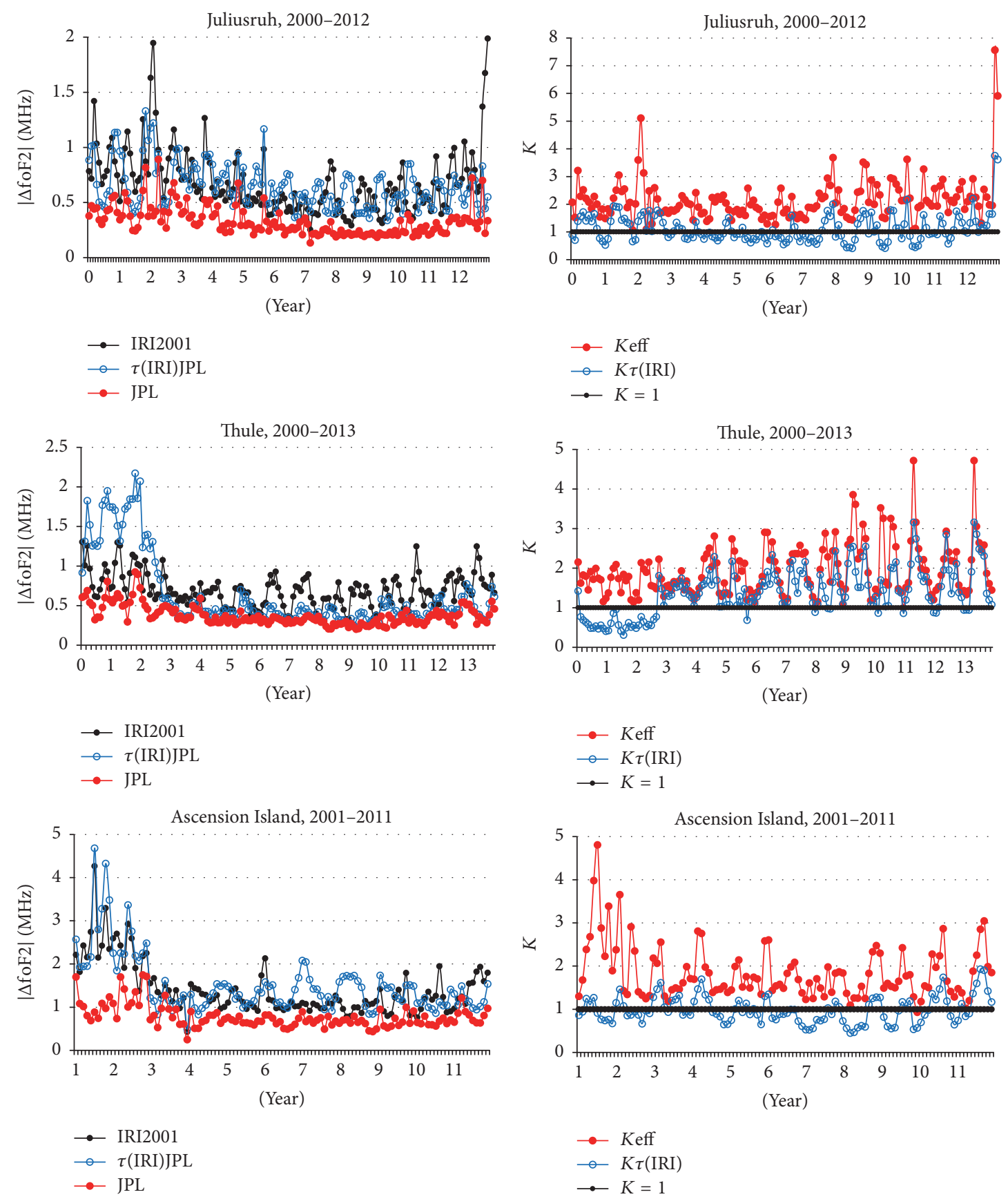

(a)

(b)

FIGURE 5: Deviations of the calculated values of foF2 from experimental foF2(obs) for following options: (1) initial model IRI (black dots), (2) joint use of TEC(obs) and $\tau$ (IRI) (dark blue circles), and (3) joint use of TEC(obs) and $\tau$ (med) (red dots) in (a) and efficiency coefficients for stations Juliusruh, Thule, and Ascension Island.

coefficient $K(\tau)=\tau$ (med) $/ \tau($ IRI), and (3) the model NGM. Regarding the first option, in paper [22], some doubts were expressed. Since the construction of the model using values of $\tau$ (obs) is not possible due to the high variability of values (in particular, presunrise peak at some latitudes), we make an attempt to use a hyperbolic approximation and coefficient $K(\tau)$. Results are illustrated for the case of March 2015 for the largest number of stations. For the hyperbolic dependence, coefficients $b 0$ and $b 1$ of $\tau$ (med) $=b 0+b 1 / \mathrm{NmF} 2$ were modeled. The results are shown for the two regions ( 2 and 4$)$ and two wider zones (Lat1 and Lat2). Zone $2\left(15^{\circ} \mathrm{E}<\lambda<40^{\circ} \mathrm{E}\right)$ includes 8 stations in the European and Russian regions. Zone $4\left(110^{\circ} \mathrm{E}<\lambda<170^{\circ} \mathrm{E}\right)$ includes 9 east stations. Area Lat1 includes 13 stations, mostly over American continent of northern and southern hemispheres. Area Lat2 includes 20 stations from European, Siberian, and south-eastern 

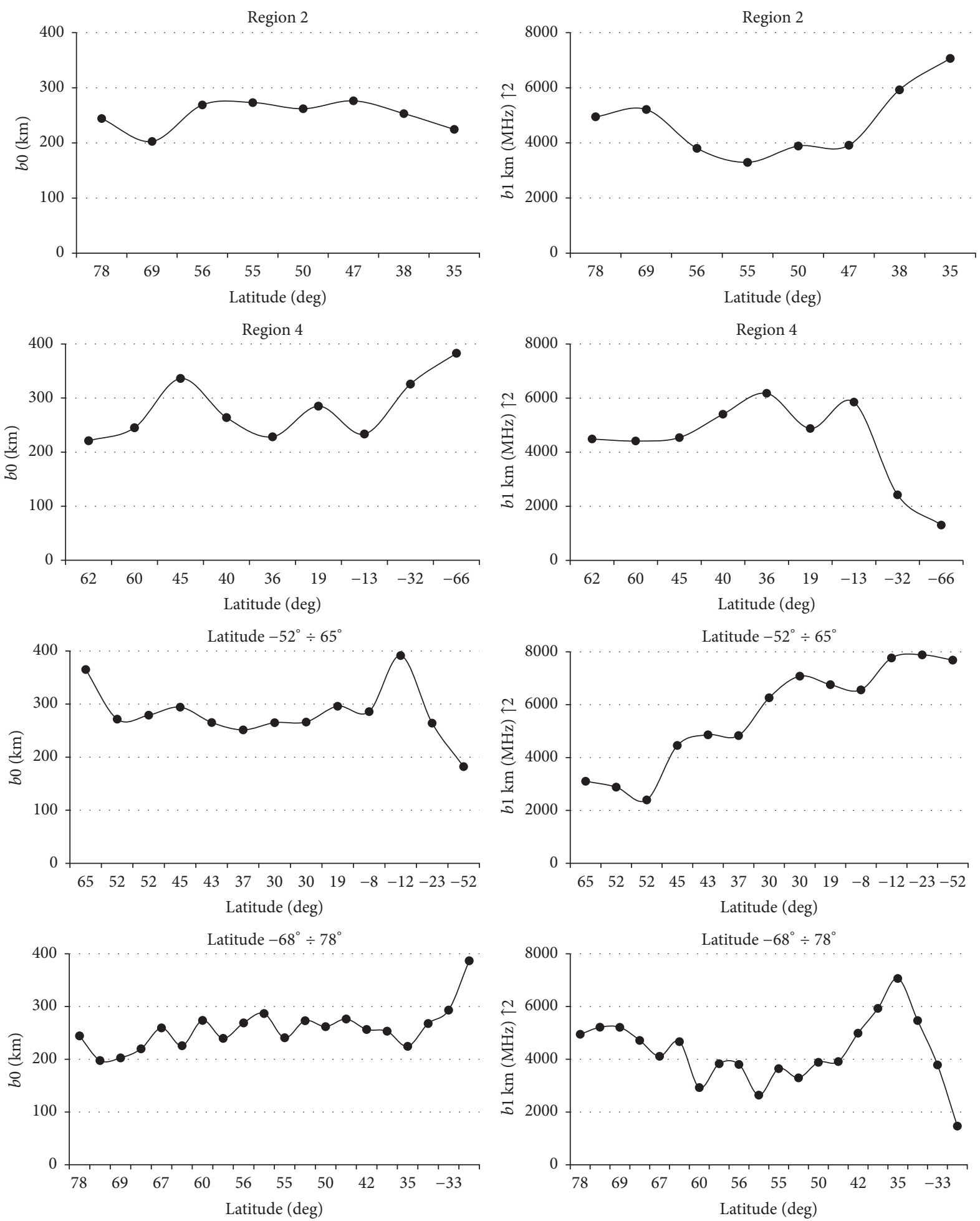

FIGURE 6: Behavior of hyperbolic approximation coefficients for various latitudinal zones.

regions. Behavior of the coefficients $b 0$ and $b 1$ for these regions is shown in Figure 6. The axis $x$ shows a latitude of stations.

Average values were calculated. They are $250.62 \mathrm{~km}$ and $4757.36 \mathrm{~m}^{-2}$ for zone $2,280.21 \mathrm{~km}$ and $4386.01 \mathrm{~m}^{-2}$ for zone
4, $282.92 \mathrm{~km}$ and $5581.81 \mathrm{~m}^{-2}$ for Latl area, and $257.63 \mathrm{~km}$ and $4276.64 \mathrm{~m}^{-2}$ for Lat2 zone. Results are shown in Table 1. The table contains the following data. Column 1 indicates the station name and its location (corresponding region). The second column shows the coefficients of the hyperbolic 
TABLE 1: Deviations of frequencies calculated according to the hyperbolic approximation from experimental values in April 2014.

\begin{tabular}{|c|c|c|c|c|c|c|c|c|c|}
\hline 1 & 2 & 3 & 4 & 5 & 6 & 7 & 8 & 9 & 10 \\
\hline station & $b 1, b 0$ & & IRI & Rec & Stat & Reg 2 & Reg 4 & Lat 1 & Lat 2 \\
\hline Juliusruh & 3295.5 & $\mathrm{f}$ & 0.73 & 0.41 & 0.43 & 0.68 & 0.67 & 1.03 & 0.57 \\
\hline Reg 2 & 273.2 & d & 1.44 & 0.52 & 0.49 & 0.67 & 0.68 & 1.07 & 0.64 \\
\hline Athens & 5929.3 & $\mathrm{f}$ & 0.91 & 0.36 & 0.46 & 0.56 & 0.48 & 0.52 & 0.58 \\
\hline Reg 2 & 253.2 & $\mathrm{~d}$ & 1.31 & 0.44 & 0.74 & 0.52 & 0.59 & 0.87 & 0.51 \\
\hline Grahams & 3788.7 & $\mathrm{f}$ & 0.8 & 0.4 & 0.54 & 0.77 & 0.59 & 0.73 & 0.73 \\
\hline Lat 2 & 293.2 & $\mathrm{~d}$ & 1.54 & 0.46 & 0.62 & 0.84 & 0.75 & 0.82 & 0.77 \\
\hline Longyear & 4947.1 & $\mathrm{f}$ & 0.7 & 0.43 & 0.62 & 0.6 & 0.58 & 0.82 & 0.58 \\
\hline Lat 2 & 244.2 & $\mathrm{~d}$ & 0.69 & 0.49 & 0.73 & 0.69 & 0.69 & 1.01 & 0.63 \\
\hline \multirow{2}{*}{ Thule } & 692.7 & $\mathrm{f}$ & 0.51 & 0.14 & 0.15 & 0.56 & 0.42 & 0.47 & 0.59 \\
\hline & 437.6 & $\mathrm{~d}$ & 0.55 & 0.1 & 0.13 & 0.51 & 0.46 & 0.64 & 0.54 \\
\hline Millstone & 4864.4 & $\mathrm{f}$ & 0.9 & 0.5 & 0.47 & 0.48 & 0.46 & 0.67 & 0.49 \\
\hline Lat 1 & 265.4 & d & 1.38 & 0.67 & 0.67 & 0.65 & 0.81 & 0.81 & 0.8 \\
\hline Beijing & 5402.8 & $\mathrm{f}$ & 1.17 & 0.49 & 0.61 & 0.61 & 0.58 & 0.7 & 0.62 \\
\hline Reg 4 & 263.9 & d & 1.99 & 0.42 & 0.64 & 0.45 & 0.51 & 0.84 & 0.45 \\
\hline Kokubunji & 6176.7 & $\mathrm{f}$ & 1.29 & 0.47 & 0.65 & 0.61 & 0.69 & 0.85 & 0.62 \\
\hline $\operatorname{Reg} 4$ & 228.4 & d & 2.11 & 0.55 & 0.66 & 0.56 & 0.7 & 0.96 & 0.56 \\
\hline Niue & 4874.7 & $\mathrm{f}$ & 1.85 & 1.15 & 1.36 & 1.35 & 1.28 & 1.43 & 1.29 \\
\hline Reg 4 & 285 & $\mathrm{~d}$ & 1.67 & 0.71 & 1 & 0.73 & 0.85 & 1.11 & 0.67 \\
\hline Cocos & 5467.3 & $\mathrm{f}$ & 1.43 & 0.55 & 0.68 & 0.86 & 0.62 & 0.65 & 0.82 \\
\hline Lat 2 & 267.8 & d & 1.66 & 0.52 & 0.77 & 0.88 & 0.67 & 0.8 & 0.83 \\
\hline Mawson & 1466.2 & $\mathrm{f}$ & 0.91 & 0.27 & 0.37 & 1 & 0.85 & 1.02 & 0.92 \\
\hline Lat 2 & 386.8 & $\mathrm{~d}$ & 1.12 & 0.12 & 0.21 & 0.8 & 0.98 & 0.98 & 0.81 \\
\hline
\end{tabular}

dependence of $\tau$ (obs) according to the respective station. The third column specifies the conditions to which the two rows of values belong. The top line indicates average for all days of the month, at the bottom, the average for disturbed days (from 16 to 21 March). Symbol $f$ means full month and $d$ concerns magnitudes averaged on disturbed days. The fourth column shows the results for the initial IRI model and the fifth one the absolute difference between the experimental values foF2(obs) and values calculated using TEC(obs) and $\tau$ (med).

Column 6 contains deviations of frequencies calculated using the coefficients $b 0$ and $b 1$ of the hyperbolic approximation for a given station. The rest columns give results using the coefficients of the areas referred to in the column header. All of these values should be compared with values of the IRI model in bold.

It can be seen that all values are larger in disturbed days and the largest differences correspond to the initial IRI model. The table illustrates opportunity to use the coefficients of one region for the calculation of foF 2 of other zones. This demonstrates a global character of the $\tau$ (med) model.

One important issue is the dependence of the coefficients on solar activity. Figure 7 shows the coefficients $b 0$ and $b 1$ for different years, arranged in descending order of solar activity.

The use of coefficients $K(\tau)$ can be another method of constructing the global $\tau$ (med) model. Definite advantage of this model might be in the fact what in its denominator is the value of $\tau$ (IRI), which has a global character, and a small change of $K(\tau)$ in areas with close latitudes. Distinctive feature is a development of a model for each hour. The degree of proximity of values is best illustrated in the circular charts. An example of some charts is shown in Figure 8 for region 4 , for $\mathrm{UT}=0,6,12$, and 18 in March 2015. The red line shows the value of the coefficient $K(\tau)$; green points are the average values and the blue marks mean a circle with radius $R=1$. Besides dots values of latitudes of used stations are given.

The model is the average value $K$ (mean). The algorithm of its use is reduced to what the new value $\tau(K \tau)=K($ mean $) *$ $\tau$ (IRI) is computed and this new value is used together with the experimental value of the TEC to calculate foF2. To test the algorithm, $K$ (mean) averages were calculated for 7 stations and used to calculate foF 2 for the 8th station. Results in the form of deviations of calculated foF2 values from foF2(obs) are presented for the four experimental stations: Pruhonice, Gorkovskaya, Tunguska, and Ramey in Figure 9.

Black dots show differences between values of foF2(IRI) of the IRI model and observational values foF2(obs) (symbol IRI). Blue dots indicate deviations in the case of joint use of TEC(obs) and $\tau$ (IRI) (symbol $\tau($ IRI)). Green triangles represent the results for the case of joint use of TEC(obs) and $\tau$ (med) (symbol $\tau$ (med)). Red diamond shows deviations for joint use of TEC(obs) and a new coefficient $\tau(K \tau)$ (symbol new). Zones, which included stations Pruhonice, Gorkovskaya, and Ramey, consist of 8 stations. The 

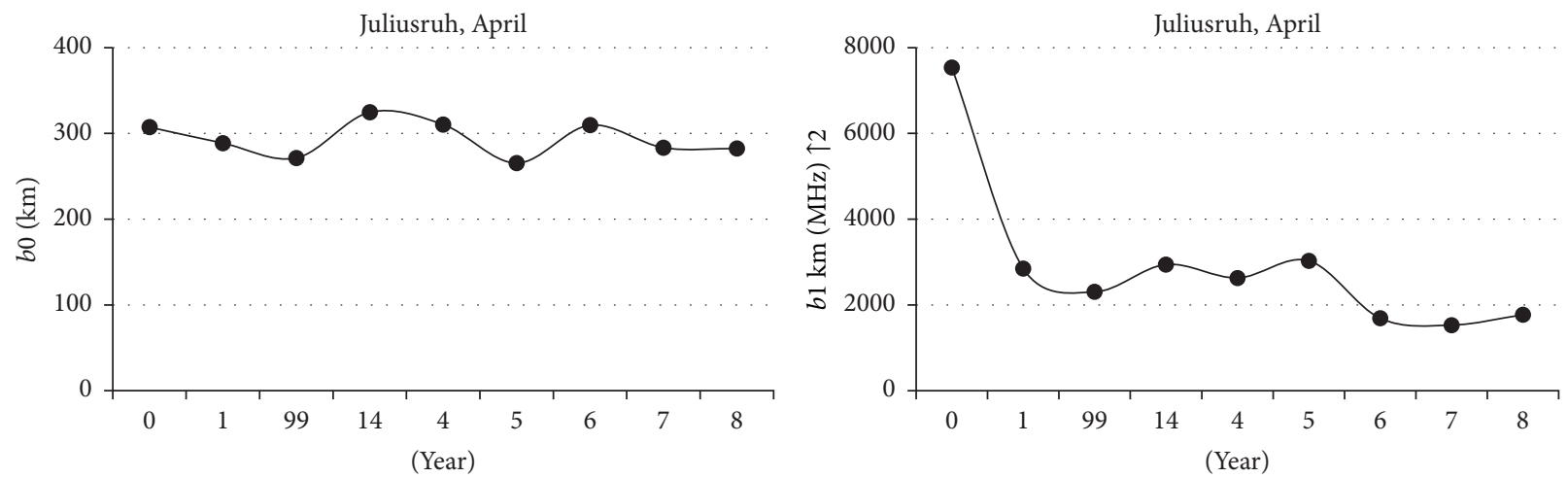

FIgURE 7: The behavior of the coefficients $b 0$ and $b 1$ of the hyperbolic approximation for the Juliusruh station for April of several years.
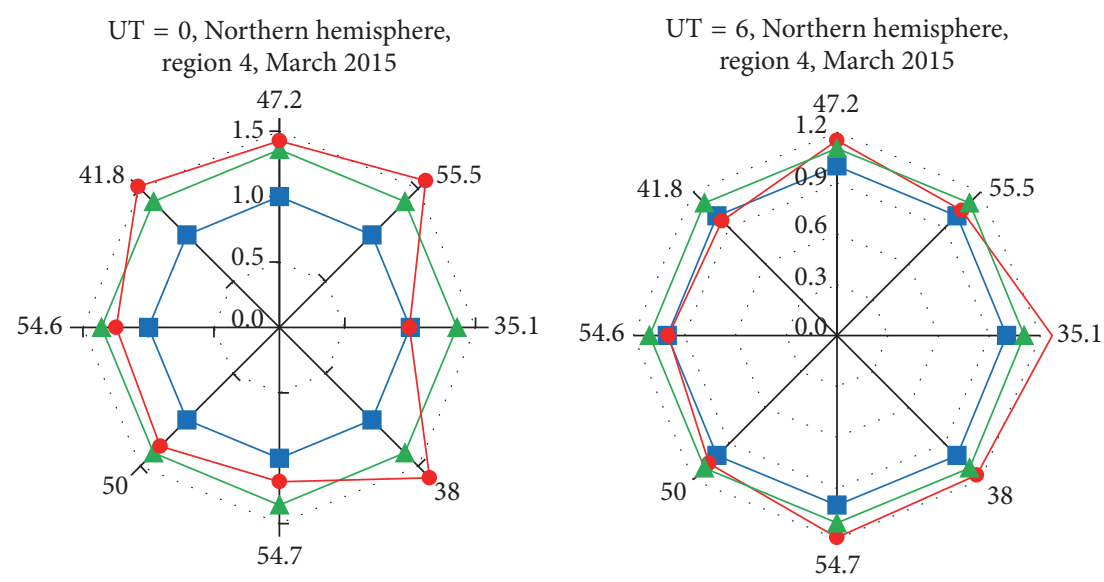

$$
\begin{aligned}
& \multimap K=1 \\
& -K(\tau)
\end{aligned}
$$

$\mathrm{UT}=12$, Northern hemisphere, region 4, March 2015
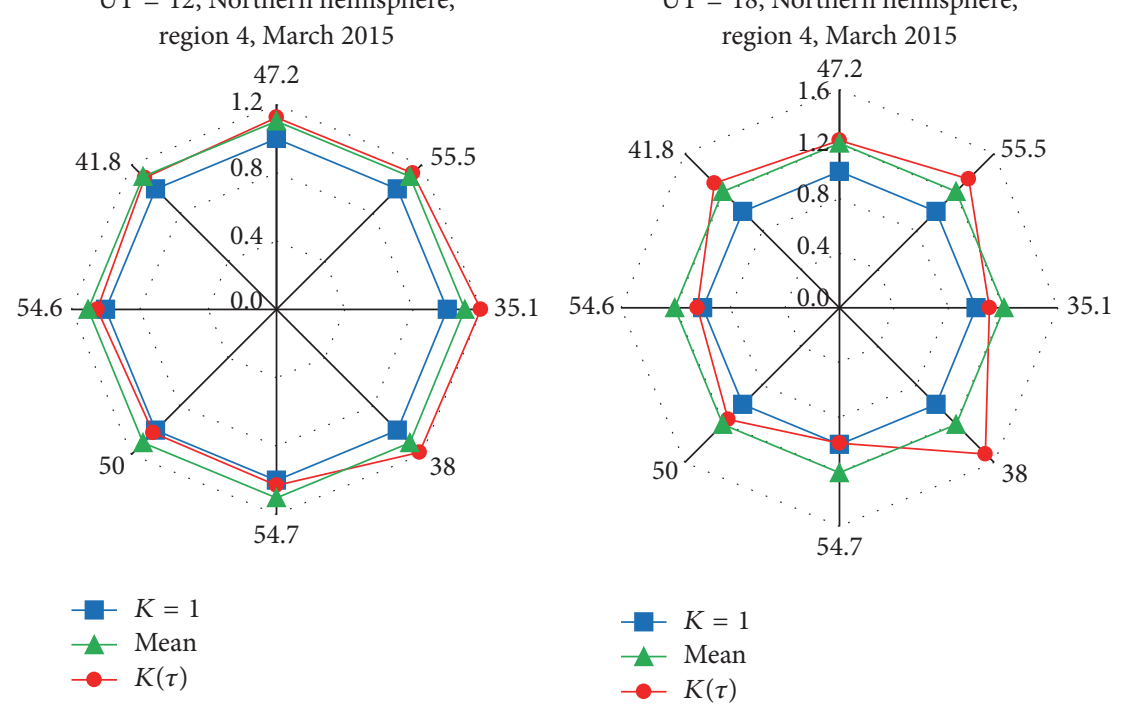

FIGURE 8: Illustration of diagrams for the coefficient $K(\tau)$ for region 4 and various moments UT. 

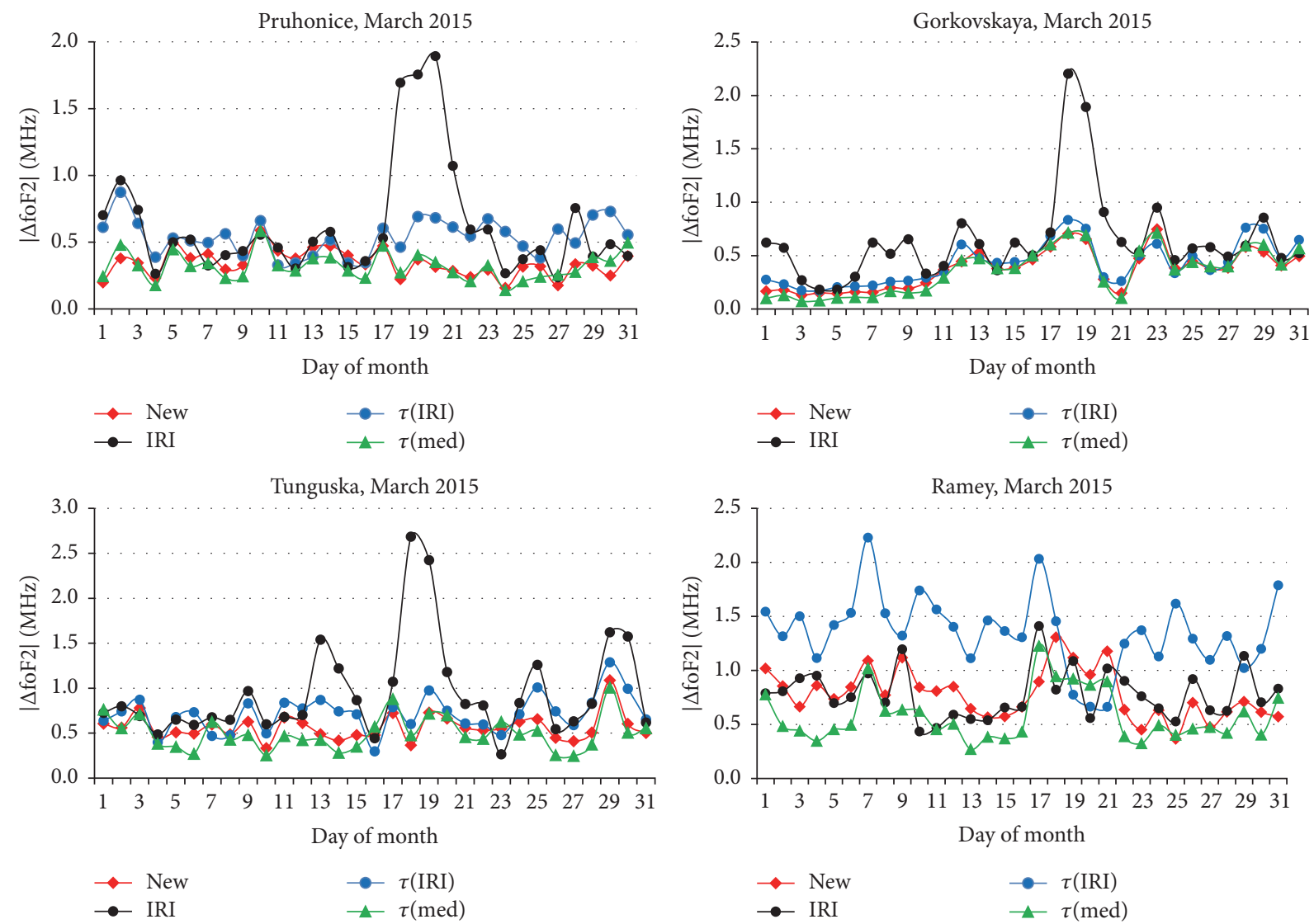

FIGURE 9: Deviations of calculated values from experimental foF2(obs) for different options of using TEC(obs). Black dots show curves for the initial model IRI. Blue dots indicate curves for a case of joint use of TEC(obs) and $\tau$ (IRI). Green triangles represent curves for a case of joint use of TEC(obs) and $\tau$ (med). Red diamond show curves for use of coefficient of the model $K(\tau)$.

coefficient $\tau(K \tau)$ was calculated by the values of $K(\tau)$ of seven stations. For the Tunguska station, area includes 6 stations, and the coefficient was calculated according to 5 stations.

Except disturbed days (17-20 March) average foF2(IRI) corresponds to instantaneous values well. The use of TEC(obs) with $\tau$ (IRI) improves the results of the initial model (previous curve) except case of the Ramey Station. The use of the TEC(obs) with a median $\tau$ (med) gives the better coincidence with observational values foF2(obs). Naturally, the value of $\mid \Delta$ foF $2 \mid$ for the model $K(\tau)$ is slightly larger than for $\tau$ (med), but less than for the other options. This testifies to a possibility of development of the global model of $\tau$ (med).

\section{Additional Comments Concerning Use of TEC(obs)}

In Introduction, a series of advantages of the use of TEC for calculation of foF2 was marked; however there is also a series of shortages. It is possible to name among them the following: dependence of TEC on type of receivers [23], a large number of methods, and TEC values which can deviate up to 2 and more times [24]. In papers [17, 20, 25] of authors of this article, the large attention was given to influence of differences of TEC on values of foF2. On an example of global maps JPL, CODE, UPC, and ESA it was shown that, despite the large differences of TEC, deviations $\mid \Delta$ foF $2 \mid$ were less than deviations for the initial IRI model practically for all maps. It testifies to good calibration properties of the equivalent slab thickness $\tau$, reducing influence of differences of TEC. In most cases, the least values of $\mid \Delta$ foF $2 \mid$ are provided by the JPL map. Very close results were obtained for the CODE map. The reasonable compromise is the utilization of values IGS which are robust averages from values of 4 maps [26]. For them values of $\mid \Delta$ foF2 $\mid$ lie between values for JPL and CODE maps. The use of $\tau$ (med) can play an important role for an estimation of foF 2 during disturbances and for filling of gaps of the data. Examples for these cases are given in Figures 10-12 for disturbances of April 2001 according to stations Juliusruh, Thule, and Loparsk. Results are presented in the form of daily dependences of TEC and foF2 for several days. Experimental values of TEC are given together with medians; results for foF2 are given for 4 options: (1) experimental instantaneous values (symbol obs), (2) values of the initial IRI model (symbol IRI), (3) values calculated with use of TEC(obs) and $\tau$ (med) and designated by symbol rec, and (4) monthly medians of foF2 (symbol med).

Figure 10 shows two disturbances: positive and negative when values of foF 2 essentially differ from medians. The 

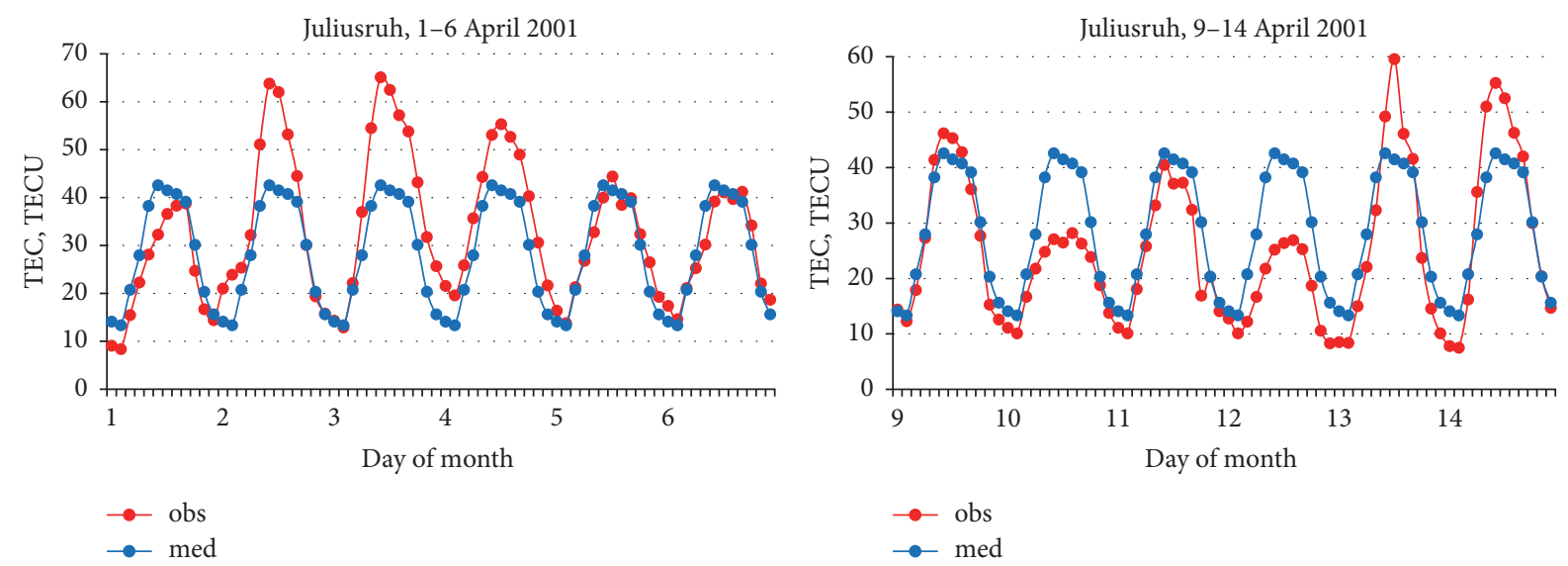

(a)
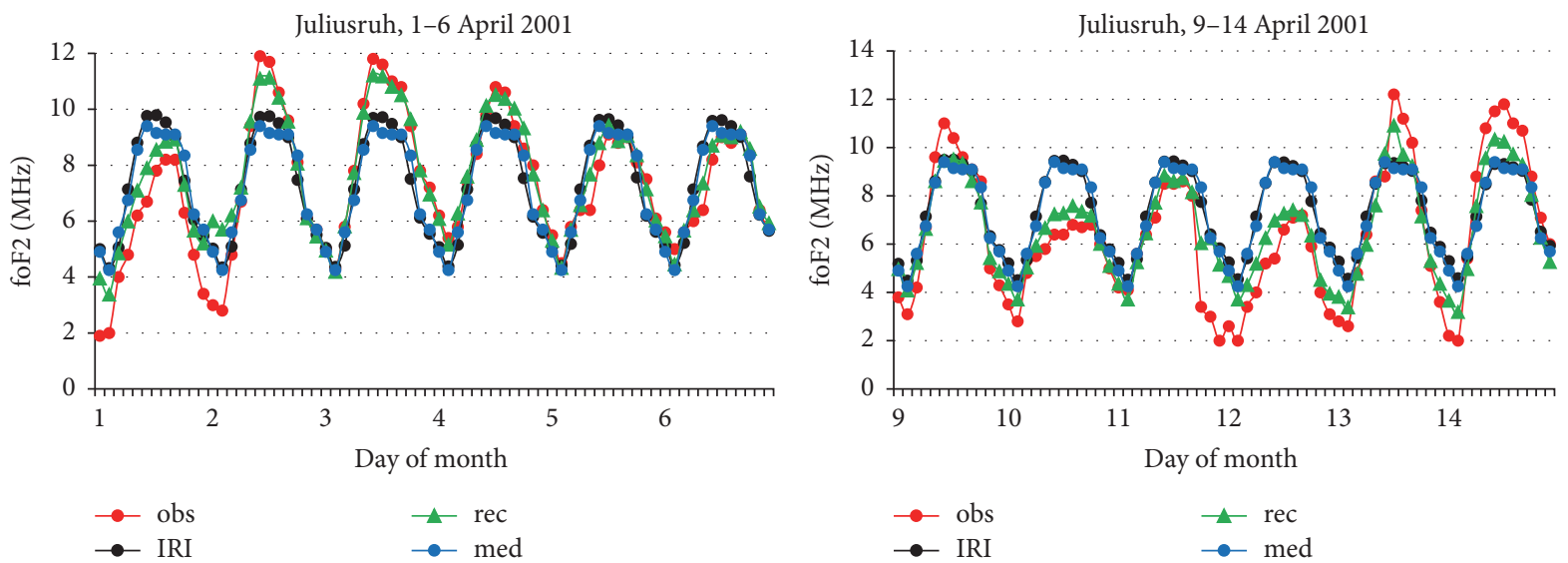

(b)

FIgURE 10: Behavior of TEC and foF2 during disturbances according to the midlatitude Juliusruh station in April 2001. On (a) experimental curves of TEC are shown by red dots; blue dots concern curves for medians. On (b) experimental curves of foF 2 are shown by red dots. Black dots show curves for the initial model IRI. Green triangles represent curves for a case of joint use of TEC(obs) and $\tau$ (med). Blue dots concern curves for medians.

proximity of values for the IRI model to medians testifies to high quality of the model which is median one and cannot reflect instantaneous values. Values of the third option are closest to foF2(obs) and reflect disturbed conditions. Figure 11 concerns the auroral Thule station

Perturbations also have positive and negative character. Both have a global character. In this case data of foF2(obs) were available only in the first period and here values for the third option are closest to foF2(obs). However in this case values of the initial model essentially differ from medians. In the second period, observational data of foF 2 were not available, but strong negative perturbation in behavior of TEC is seen. It is possible to assume that the critical frequency could experience strong negative perturbation during these periods according to the values reconstructed with use of TEC(obs) and $\tau(\mathrm{med})$. For confirmation of such character of behavior, it is possible to use data of other high-latitude stations. Data of the Tromso was available for three days but, in these days, some values were absent; for the Sodankula station all the days had the incomplete information.
The Loparsk station was chosen having the fullest data though often the F2 layer was shielded by sporadic layers Es. Results of calculations are presented in Figure 12. One can see the positive and negative disturbances. In the first period, the IRI model and case of joint use of TEC(obs) and $\tau$ (med) showed values exceeding the median. Nevertheless, there is a better match with foF2(obs) than the median. In the second period only TEC(obs) together with $\tau$ (med) has provided negative deviations from the median and a better match with foF2(obs). Average coefficients $K$ eff and $K \tau$ IRI were equal to 1.2 and 1.1 in the first period and 3.5 and 2.9 in the second period.

Thus, the use of $\tau$ (med) and TEC(obs) allows defining character of perturbation and to calculate values of foF 2 more accurately.

\section{Conclusions}

With the advent of the navigation satellites providing measurement of the total electron content of the ionosphere, this 

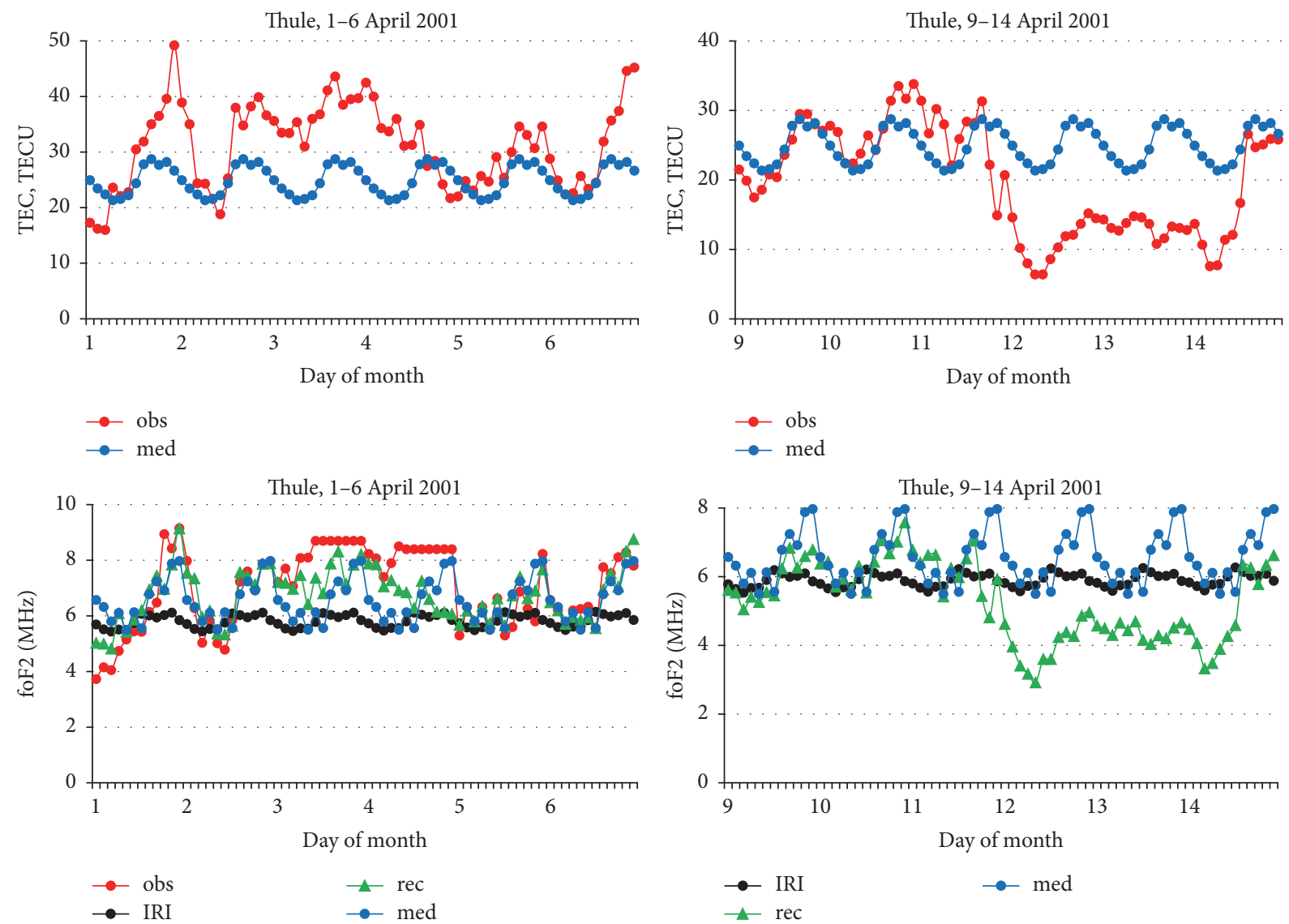

FIGURE 11: Behavior of TEC and foF2 during disturbances according to the auroral Thule station. Representation of curves is similar to Figure 10.

parameter has got the large practical value. In the presented paper, opportunity of use of observational values TEC(obs) to estimate disturbed conditions is investigated, and, as an example, stations with long-term arrays of observation are chosen in all regions of globe from high latitudes to equatorial area. The key role belongs to an equivalent slab thickness of the ionosphere. Results are presented as comparison of deviations of the calculated values of the critical frequency foF2 from experimental magnitudes foF2(obs) for 3 options: (1) initial model, (2) joint use of TEC(obs) and $\tau$ (IRI), and (3) joint use of TEC(obs) and $\tau$ (med). The main conclusions are as follows.

(1) It is shown that the model IRI provides good conformity of calculated foF2 with experimental medians; however values of $\tau(\mathrm{IRI})$ strongly differ from an experimental median $\tau$ (med) both on magnitude and on character of daily variations.

(2) Joint use of TEC(obs) and $\tau$ (IRI) not always improves results of the initial model.

(3) Joint use of TEC(obs) and $\tau$ (med) always improves results of the initial model. Thus, because of calibration properties of $\tau$ (med) (good match to TEC(obs)) results for all global maps, TEC values which can differ 1.5-2 times are better than for the initial model. The map JPL provides the best conformity with foF2(obs) in most cases. Close results can correspond to the map CODE.

(4) Experimental values of foF2 are often absent during disturbances. In this case, TEC is a unique source of the information on character of disturbances, and joint use of TEC(obs) and $\tau$ (med) allows estimating foF2 and filling gaps of vertical sounding data.

(5) The positive fact is attempt of construction of empirical model of $\tau$ (NGM, Muslim et al. [10]) which has shown that for any model there are regions and conditions of solar activity at which the model provides the better results than the initial model. Two approaches, offered in the given paper, specify opportunity of construction of model $\tau$, improving results of the initial model on a global scale.

\section{Competing Interests}

The authors declare that there are no competing interests regarding the publication of this paper. 

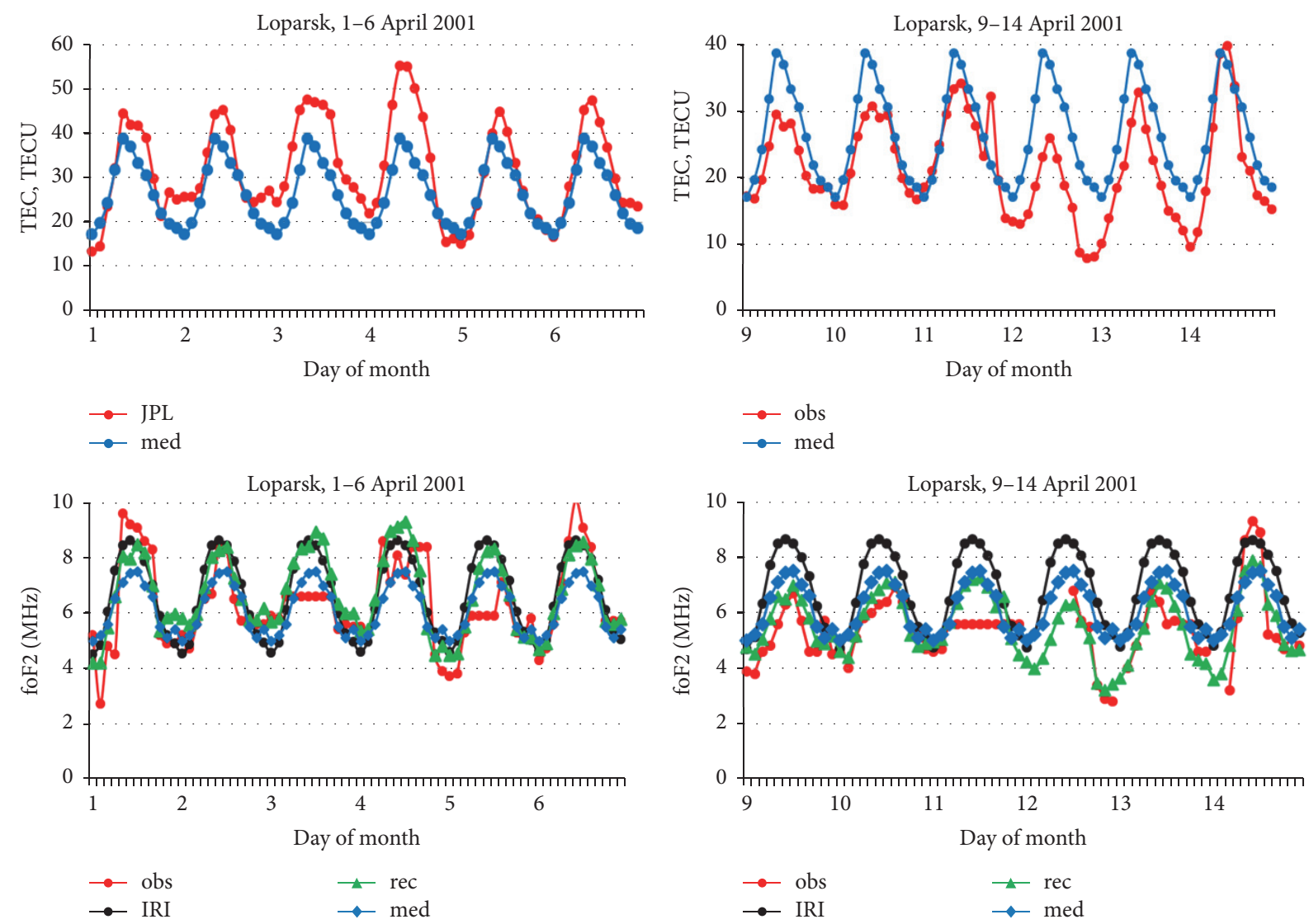

FIGURE 12: Behavior of TEC and foF2 during disturbances according to the high latitude Loparsk station. Representation of curves is similar to Figure 10 .

\section{Acknowledgments}

The authors thank the scientists who provided data of SPIDR, global maps of TEC, and operation and modification of the IRI model. The work of Olga Maltseva was supported by Southern Federal University Grant no. 213.01-11/2014-22.

\section{References}

[1] J. M. Goodman, "Operational communication systems and relationships to the ionosphere and space weather," Advances in Space Research, vol. 36, no. 12, pp. 2241-2252, 2005.

[2] Y. Kakinami, C. H. Chen, J. Y. Liu, K.-I. Oyama, W. H. Yang, and S. Abe, "Empirical models of total electron content based on functional fitting over Taiwan during geomagnetic quiet condition," Annales Geophysicae, vol. 27, no. 8, pp. 3321-3333, 2009.

[3] A. Ercha, D. Zhang, A. J. Ridley, Z. Xiao, and Y. Hao, "A global model: empirical orthogonal function analysis of total electron content 1999-2009 data," Journal of Geophysical Research: Space Physics, vol. 117, no. 3, Article ID A03328, 2012.

[4] V. B. Ivanov, G. D. Gefan, and O. A. Gorbachev, "Global empirical modelling of the total electron content of the ionosphere for satellite radio navigation systems," Journal of Atmospheric and Solar-Terrestrial Physics, vol. 73, no. 13, pp. 1703-1707, 2011.

[5] J. A. Klobuchar, "Ionospheric time-delay algorithm for singlefrequency GPS users," IEEE Transactions on Aerospace and Electronic Systems, vol. 23, no. 3, pp. 325-331, 1987.
[6] K. Chen and Y. Gao, "Real-time precise point positioning using single frequency data," in Proceedings of the 18th International Technical Meeting of the Satellite Division of the Institute of Navigation (IONGNSS '05), pp. 1514-1523, Long Beach, Calif, USA, September 2005.

[7] T. L. Gulyaeva and I. Stanislawska, "Derivation of a planetary ionospheric storm index," Annales Geophysicae, vol. 26, no. 9, pp. 2645-2648, 2008.

[8] N. Jakowski, S. M. Stankov, S. Schlueter, and D. Klaehn, "On developing a new ionospheric perturbation index for space weather operations," Advances in Space Research, vol. 38, no. 11, pp. 2596-2600, 2006.

[9] D. Bilitza, D. Altadill, Y. Zhang et al., "The International Reference Ionosphere 2012-a model of international collaboration," Journal of Space Weather and Space Climate, vol. 4, article A07, 12 pages, 2014.

[10] B. Muslim, H. Haralambous, C. Oikonomou, and S. Anggarani, "Evaluation of a global model of ionospheric slab thickness for foF2 estimation during geomagnetic storm," Annals of Geophysics, vol. 58, no. 5, Article ID A0551, 2015.

[11] T. L. Gulyaeva, "International standard model of the Earth's inosphere and plasmasphere," Astronomical and Astrophysical Transactions, vol. 22, no. 4-5, pp. 639-643, 2003.

[12] T. L. Gulyaeva, "Storm time behavior of topside scale height inferred from the ionosphere-plasmasphere model driven by the F2 layer peak and GPS-TEC observations," Advances in Space Research, vol. 47, no. 6, pp. 913-920, 2011. 
[13] Z. Houminer and H. Soicher, "Improved short-term predictions of $\mathrm{f}_{0} \mathrm{~F}_{2}$ using GPS time delay measurements," Radio Science, vol. 31, no. 5, pp. 1099-1108, 1996.

[14] T. Gerzen, N. Jakowski, V. Wilken, and M. M. Hoque, "Reconstruction of F2 layer peak electron density based on operational vertical total electron content maps," Annales Geophysicae, vol. 31, no. 7, pp. 1241-1249, 2013.

[15] M. M. Hoque and N. Jakowski, "A new global empirical NmF2 model for operational use in radio systems," Radio Science, vol. 46, no. 6, Article ID RS6015, pp. 1-13, 2011.

[16] N. Jakowski, M. M. Hoque, and C. Mayer, "A new global TEC model for estimating transionospheric radio wave propagation errors," Journal of Geodesy, vol. 85, no. 12, pp. 965-974, 2011.

[17] O. A. Maltseva, N. S. Mozhaeva, and T. V. Nikitenko, "Validation of the Neustrelitz Global Model according to the low latitude ionosphere," Advances in Space Research, vol. 54, no. 3, pp. 463472, 2014.

[18] N. Sardar, A. K. Singh, A. Nagar, S. D. Mishra, and S. K. Vijay, "Study of latitudinal variation of ionospheric parameters-a detailed report," Journal of Indian Geophysical Union, vol. 16, no. 3, pp. 113-133, 2012.

[19] O. A. Maltseva and N. S. Mozhaeva, "Comparison of HF propagation conditions for the European mid-latitudinal and subauroral paths," in Proceedings of the Nordic HF Conference (HF '10), pp. 1-10, Faro, Portugal, 2010.

[20] O. A. Maltseva, N. S. Mozhaeva, and T. V. Nikitenko, "Comparison of model and experimental ionospheric parameters at high latitudes," Advances in Space Research, vol. 51, no. 4, pp. 599-609, 2013.

[21] O. A. Maltseva, N. S. Mozhaeva, and G. M. Glebova, "Global maps of TEC and conditions of radio wave propagation in the Mediterranean area," in Proceedings of the Progress in Electromagnetics Research Symposium (PIERS '11), pp. 1-5, Marrakesh, Morocco, March 2011.

[22] S. M. Stankov and R. Warnant, "Ionospheric slab thicknessanalysis, modelling and monitoring," Advances in Space Research, vol. 44, no. 11, pp. 1295-1303, 2009.

[23] B.-K. Choi, J.-K. Chung, and J.-H. Cho, "Receiver DCB estimation and analysis by types of GPS receiver," Journal of Astronomy and Space Science, vol. 27, no. 2, pp. 123-128, 2010.

[24] F. Arikan, C. B. Erol, and O. Arikan, "Regularized estimation of vertical total electron content from Global Positioning System data," Journal of Geophysical Research, vol. 108, no. 12, 1469, pp. 1-12, 2003.

[25] O. A. Maltseva, N. S. Mozhaeva, O. S. Poltavsky, and G. A. Zhbankov, "Use of TEC global maps and the IRI model to study ionospheric response to geomagnetic disturbances," Advances in Space Research, vol. 49, no. 6, pp. 1076-1087, 2012.

[26] M. Hernández-Pajares, J. M. Juan, J. Sanz et al., "The IGS VTEC maps: a reliable source of ionospheric information since 1998," Journal of Geodesy, vol. 83, no. 3-4, pp. 263-275, 2009. 


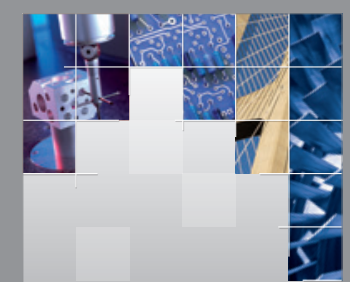

\section{Enfincering}
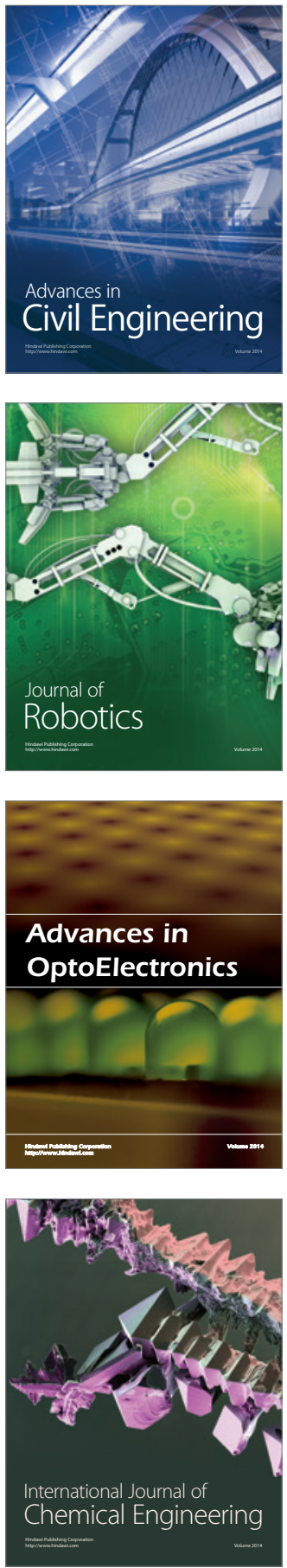

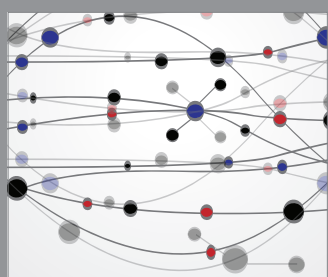

The Scientific World Journal

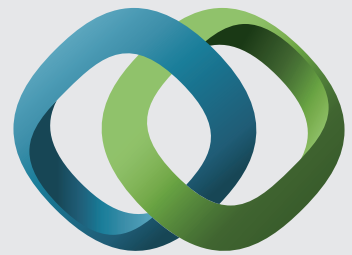

\section{Hindawi}

Submit your manuscripts at

http://www.hindawi.com
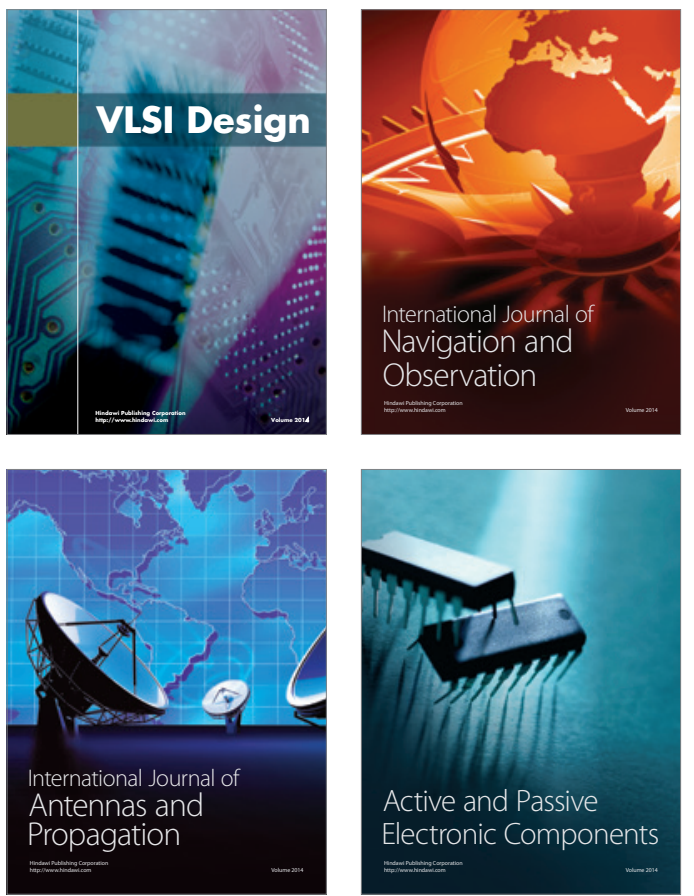
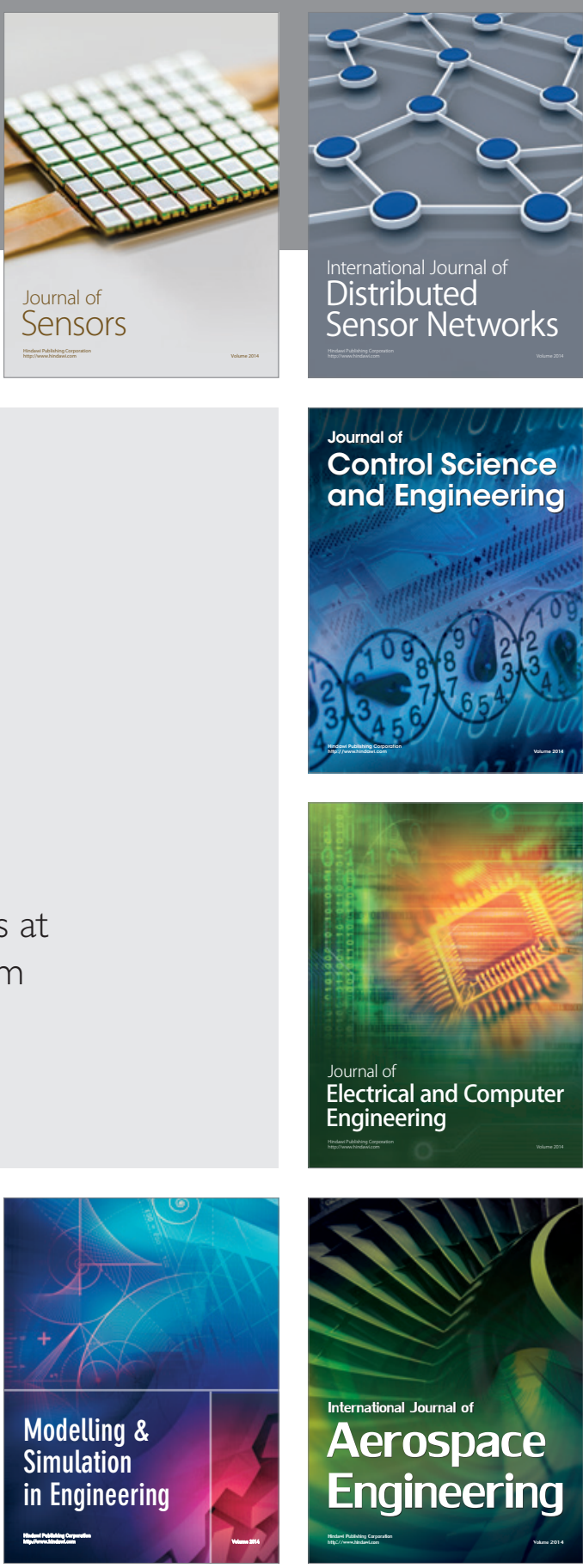

International Journal of

Distributed

Sensor Networks

Journal of

Control Science

and Engineering
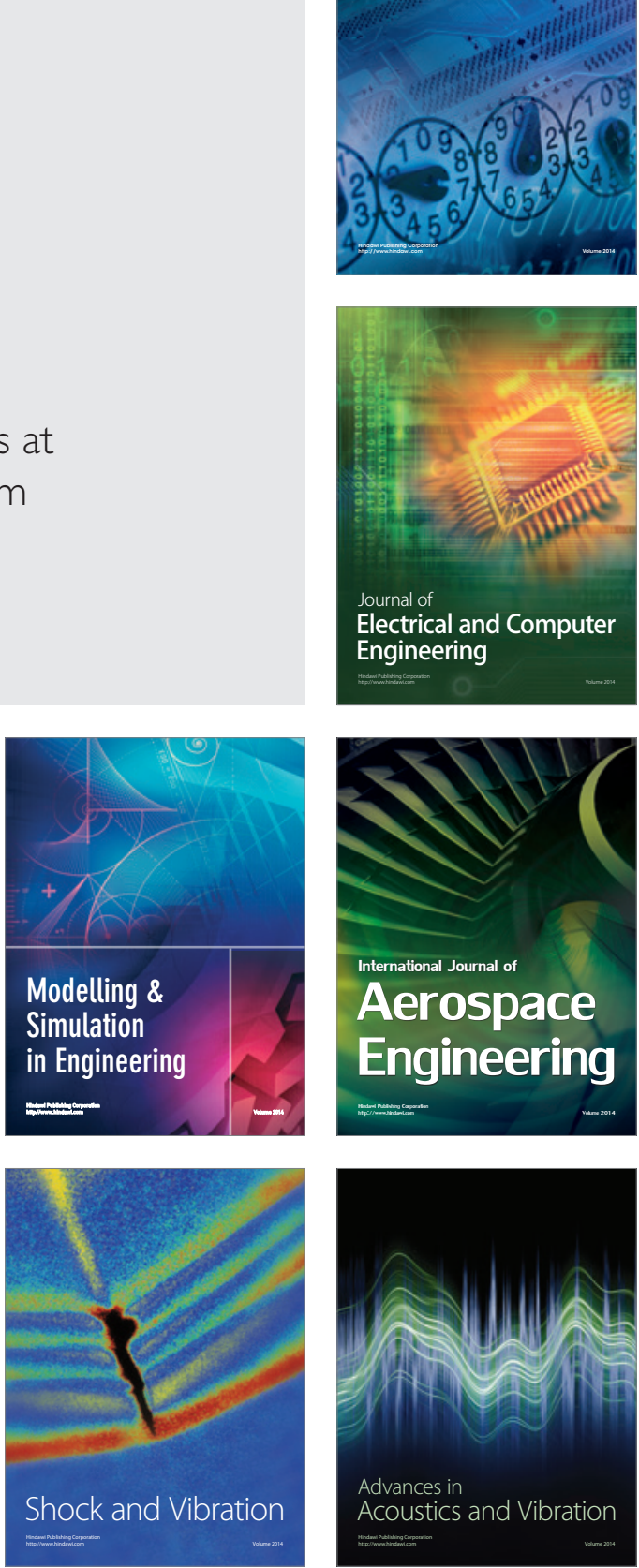